\title{
Relationship between cartilage oligomeric matrix protein (COMP) and rheumatoid arthritis severity
}

Massoud Saghafi ${ }^{1}$, Mandana Khodashahi ${ }^{2}$, Nayyereh Saadati ${ }^{3}$, Azita Azarian ${ }^{4}$, Zahra Rezaieyazdi ${ }^{1}$, Maryam Salehi ${ }^{5,6}$, Maryam Sahebari ${ }^{3}$

${ }^{1}$ MD of Rheumatology, Professor, Rheumatic Diseases Research Center, Mashhad University of Medical Sciences, Mashhad, Iran

${ }^{2}$ MD of Rheumatology, Assistant Professor, Rheumatic Diseases Research Center, Mashhad University of Medical Sciences, Mashhad, Iran

${ }^{3}$ MD of Rheumatology, Associate Professor, Rheumatic Diseases Research Center, Mashhad University of Medical Sciences, Mashhad, Iran

${ }^{4}$ MD of Radiology, Associate Professor, Department of Radiology, Faculty of Medicine, Mashhad University of Medical Sciences, Mashhad, Iran

${ }^{5}$ MD of Community Medicine, Associate Professor, Research Center for Patient Safety, Mashhad University of Medical Sciences, Mashhad, Iran

${ }^{6}$ Clinical Research Center, Ghaem Hospital, Mashhad University of Medical Sciences, Mashhad, Iran

Type of article: Original

\begin{abstract}
Background: Serum cartilage oligomeric matrix protein (COMP) is a non-collagen glycoprotein produced by the cartilage, synovium, tendon, and meniscus. Recent studies showed that COMP is a reliable factor for monitoring cartilage damage.

Objective: To determine the relationship between serum COMP concentration and the severity of rheumatoid arthritis (RA).

Methods: This cross-sectional study lasted from 2013 to 2015 at the Rheumatology Clinic of Ghaem Hospital, Mashhad, Iran. The study population consisted of eligible patients who presented to our clinic during the study period. Four groups (150 subjects) were included as early RA (50 patients), late RA (50 patients), grades II and III OA (osteoarthritis) (25 cases, 17 grade II and 8 grade III joint destruction), and healthy controls (25 individuals). These were included consecutively. Serum COMP level was assessed by sandwich ELISA technique. In addition, ESR, hs-CRP, serum RF, and anti-CCP were assayed. X-rays of the knees (in OA) and hands (in RA) were examined for the degree of joint damage/erosion using the Short Erosion Scale (SES) in RA and Kellgren-Lawrence grading in OA. Analysis of variance (ANOVA) to compare mean COMP level among the groups and ROC (Receiver Operating Characteristic) analysis to determine the diagnostic accuracy of COMP in diagnosis of late RA were used by SPSS software (ver. 20.0).

Results: Mean $( \pm$ SD) serum COMP levels were $18( \pm 10.6)$ U/L in early RA, $19.3( \pm 9.6)$ U/L in late RA, 10.9 $( \pm 4.5) \mathrm{U} / \mathrm{L}$ in OA, and $4.2( \pm 3.8)$ in controls; $\mathrm{p}<0.001$. Serum COMP level was higher in RA and OA groups when compared to control group. Mean $( \pm \mathrm{SD})$ SES score was $13.5( \pm 7.5)$ in early RA and $16.4( \pm 9.7)$ in late RA $(\mathrm{p}=0.093)$. There was a significant positive correlation between COMP level and disease severity in early RA $(\mathrm{r}=0.677, \mathrm{p}<0.001)$ as well as in late RA $(\mathrm{r}=0.753, \mathrm{p}<0.001)$. Serum COMP level at a concentration of $15.25 \mathrm{U} / \mathrm{L}$ had a sensitivity of $68 \%$ and specificity of $70 \%$ to discriminate late RA from early RA (area under curve $=69 \%$ (95\% CI: $58 \%$ to $79 \%$; $\mathrm{p}=0.001$ ).

Conclusion: COMP had positive significant correlation with early and late RA severity. This serum biomarker can be a useful and easy tool for monitoring of RA patients either at early or late stages of the disease.

Keywords: Rheumatoid arthritis; Cartilage oligomeric matrix protein (COMP); Extracellular matrix proteins

\section{Corresponding author:}

Assistant Professor Dr. Mandana Khodashahi, Rheumatic Diseases Research Center, Mashhad University of Medical Sciences, Mashhad, Iran. Tel: +98.9153023711, Email: Khodashahimn@mums.ac.ir

Received: May 31, 2017, Accepted: November 15, 2017, Published: December 2017

iThenticate screening: November 16, 2017, English editing: December 10, 2017, Quality control: December 15, 2017 This article has been reviewed / commented by four experts

(C) 2017 The Authors. This is an open access article under the terms of the Creative Commons Attribution-NonCommercialNoDerivs License, which permits use and distribution in any medium, provided the original work is properly cited, the use is non-commercial and no modifications or adaptations are made.
\end{abstract}




\section{Introduction}

Rheumatoid arthritis (RA) is the most frequent autoimmune chronic inflammatory disease which involves about $1 \%$ of the white race population, and may lead to joint impairment and disability (1). Its hallmark is a peripheral symmetric polyarthritis. Systemic manifestations such as skin, eye, pulmonary and cardiovascular involvement, peripheral neuropathy, vasculitis and blood indexes abnormalities can occur during the disease progression $(2,3)$. RA severity is associated with joint destruction and disability (4). Various studies have been conducted to find the role of different biomarkers in disease progression, and abundant efforts have been performed for predicting the evolution of the condition by special biomarkers (5). Rheumatoid factor (RF) was first described in 1940 and since that time, most pathophysiologic studies in RA patients have focused on this anti-body (5). The American College of Rheumatology (ACR) described the clinical and laboratory criteria for RA (3). However, RF as one of the diagnostic criteria, is not specific enough. So, in recent decades, other antibodies have been identified in RA patients in an effort for better clarification of RA (6). For instance, anti-cyclic citrullinated peptide (anti-CCP) has been described in RA patients. Plus, it has been proposed that anti-CCP is more accurate than other markers as a diagnostic and prognostic index. Anti-CCP might be implicated in the pathophysiology of disease and associated with disease performance and joint erosions but it is not specific (7). Recent studies have been focused on new markers of joint destruction to identify RA patients who are at the risk of developing progressive joint damage. Modern biomarkers in serum and synovial fluid might be helpful in monitoring the course of RA (8). Cartilage oligomeric matrix protein (COMP) is an original molecular marker of cartilage (9). COMP is a non-collagen glycoprotein produced by the cartilage, synovium, tendon, and meniscus. Molecular studies showed that COMP can activate the complement system, interact with other proteins to maintain cartilage integrity and regulate chondrocyte function and cell death (10). Recent studies showed that COMP is a reliable factor for monitoring cartilage damage and follow up, and determining therapeutic response (11). There is evidence about the correlation between COMP level and radiologic manifestations of RA (12). This biomarker strongly correlates with joint cartilage degradation (13, 14). However, the results of all studies are not consistent. For instance, in a study on 238 RA patients who were followed for 10 years, serum COMP was not found to have significant association with radiographic progression of joint damage (15). In addition, some studies have indicated that COMP, in fact, decreases in advanced stages of RA (12). A former report noted that mean serum COMP was significantly higher in established RA $(23.9 \mathrm{micg} / \mathrm{mL})$ than in early stage RA (15.1 micg/mL) (16). Here, we decided to compare serum COMP level between RA patients and OA as well as healthy controls. In addition, we intended to explore the diagnostic accuracy of this biomarker in differentiating early stages of RA from more advanced later-stage RA to find out whether serum COMP can be used reliably to diagnose late-stage RA defined by radiographic findings of cartilage damage.

\section{Material and Methods}

\subsection{Study design and setting}

This cross-sectional study was conducted from 2013 to 2015 at the Rheumatology Clinic and Rheumatic Diseases Research Center of Ghaem Hospital, Mashhad University of Medical Sciences, Mashhad, Iran. Four groups were included consisting early RA, late RA, OA, and normal controls.

\subsection{Study population}

The study population consisted of eligible patients who presented to our clinic during the study period for follow-up of their condition. RA was diagnosed according to the guidelines of the American College of Rheumatology (ACR)/European League Against Rheumatism collaborative initiative (17) and categorized as early-stage or latestage RA. Early-stage RA was defined as pure RA, involvement of at least three joints, and disease duration of less than one year. Late-stage RA (more advanced and established RA) was described as pure RA with at least five affected joints and disease duration of more than one year. Diagnosis of OA was made considering the ACR criteria (18). Healthy controls consisted of patients who presented to our clinic during the study period complaining of nonspecific musculoskeletal symptoms, for whom the diagnoses of OA and RA had been excluded. Exclusion criteria included pregnancy, renal failure, hepatic failure, heart failure, and malignancies, overlap syndromes or collagen vascular diseases, smoking, alcohol use, immune deficiency, coagulopathies and articular trauma or intervention such as joint injection or manipulations.

\subsection{Sampling}

The sampling method was of consecutive method. Considering the main objective of the study which was comparison of serum COMP level between early- and late-stage RA, considering alpha $=5 \%$ and power of $80 \%$, and a similar study (19) the sample size was calculated as 25 subjects in each group. In order to minimize random error, 
the sample in each group was raised to 50 subjects. Similarly, 25 subjects were included for each of OA and control groups.

\subsection{Biomarkers}

Laboratory tests were conducted on $5 \mathrm{cc}$ blood samples obtained from the brachial vein. The erythrocyte sedimentation rate (ESR) and C-reactive protein (CRP) were measured by Western and immunonephelometric methods, respectively. These two markers are non-specific inflammatory biomarkers. CRP is an acute phase reactant that measures body response to acute inflammation. ESR measures the plasma viscosity by evaluating the tendency of red blood cells to aggregate (20). Serum COMP level (normal range $=0.3$ to $20 \mathrm{U} / \mathrm{L}$ ) was assessed by sandwich ELISA method (Anamor, Sweden) and anti-CCP antibody was determined by ELISA technique. Anti-CCP is a biomarker with a specificity of $95 \%$ to diagnose RA, and is one of the widely tested markers in making the diagnosis of RA (21).

\subsection{Radiologic studies}

OA patients underwent anterior-posterior (AP) and lateral radiographies of the knees. For RA patients, AP radiographic examinations of hands were performed. All radiographies were evaluated by a radiologist to determine joint damage severity. The short erosion scale (SES) was used to determine RA severity. The SES considers 12 joints: three from the four regions of the wrist (medial-proximal, medial-distal, lateral proximal), second, third and fifth metacarpophalangeal joint. Each joint was evaluated and graded as described previously (22). In OA group, the severity of joint damage was scored using the Kellgren-Lawrence grading (23). The radiologist was blinded to the laboratory examination results.

\subsection{Statistical analyses}

Descriptive statistics including frequency, percentage, mean, and its standard deviation (SD) were used to express data. In order to compare mean (SD) value of the laboratory biomarkers among the four groups, one-way analysis of variance (ANOVA) was used. Post-hoc test for ANOVA (Scheffe and Tukey tests) was performed for multiple comparisons. Next, in order to determine the relationship between severity of joint involvement (i.e., SES score in RA patients and OA severity score) and the assayed biomarkers, the Pearson's correlation test was used. Finally, ROC (Receiver Operating Characteristic) analysis was performed to calculate the accuracy (area under curve), sensitivity, specificity, positive predictive value (PPV), negative predictive value (NPV), and positive likelihood ratio (LR) of serum COMP in the discrimination of late RA vs. early RA. A p value of less than 0.05 was considered as statistically significant. The analyses were done by IBM $\odot$ SPSS $\odot$ Statistics version 22 (IBM@ Corp., Armonk, NY, USA).

\subsection{Ethics}

The study protocol was approved by the Ethics Committee of Mashhad University of Medical Sciences (Code: IR.MUMS.REC.1393.104). The study objectives were explained to the patients, and written informed consent was obtained upon enrollment into the study. The study design was in conformity with the Declaration of Helsinki.

\section{Results}

In this study, 150 individuals were included. Mean (SD) age in OA, early-stage OA, late-stage RA, and control groups were $43.8( \pm 8.3), 43.6( \pm 7.6), 44.1( \pm 6.7)$, and $47.4( \pm 5.1)$ years, respectively $(\mathrm{p}=0.064)$. Male/female ratio was not significantly different between the groups $(\mathrm{p}=0.614)$. Table 1 compares mean values of the assayed biomarkers among the studied groups. As observed, serum COMP level was significantly different between the groups $(\mathrm{p}<0.001)$. Post-hoc test showed that mean serum COMP concentration was significantly higher in late-stage RA compared to early-stage RA ( $\mathrm{p}=0.002$; mean difference $=6.04)$, OA group $(\mathrm{p}<0.001$; mean difference $=8.58)$, and control group $(\mathrm{p}<0.001$; mean difference $=15.25)$. No such significant difference existed between early-stage RA and OA group $(\mathrm{p}=0.62$, mean difference $=2.54)$. ESR level was significantly different between the groups. The Tukey post-hoc test showed that ESR was higher in early RA $(\mathrm{p}=0.041)$ and late RA $(\mathrm{p}<0.001)$ in comparison with normal controls. But this difference was not significant between OA patients and normal controls $(p=0.970)$. The serum hs-CRP level significantly differed between the groups. The Tukey test showed that serum hs-CRP was higher in patients with early RA $(p<0.001)$ and late RA $(p<0.001)$ in comparison with healthy controls. But this difference was not significant between OA patients and healthy controls $(\mathrm{p}=0.449)$. The Tukey test showed that $\mathrm{RF}$ was higher in patient with early RA $(\mathrm{p}<0.001)$ and late RA $(\mathrm{p}<0.001)$ in comparison with normal controls. But this difference was not significant between OA patients and normal controls $(\mathrm{p}=0.978)$. The Tukey test showed that antiCCP was higher in patients with early RA $(p<0.001)$ and late RA $(p<0.001)$ in comparison with normal controls $(\mathrm{p}=0.998)$. But this difference was not significant between OA patients and controls. Anti-CCP level did not 
significantly differ between early and late RA patients $(\mathrm{p}=0.109)$. Table 2 presents the correlation between RA and OA severity scores and the biomarkers. Strong positive correlations were found between serum COMP level and early RA $(r=0.753, p<0.001)$ as well as late RA $(r=0.677, p<0.001)$. ROC analysis showed that serum COMP level at a concentration of $15.25 \mathrm{U} / \mathrm{L}$ had a sensitivity of $68 \%$ and specificity of $70 \%$ to discriminate late RA from early RA (area under curve $=69 \%$ (95\% CI: 58\% to 79\%; $p=0.001)$; Table 3 and Figure 1 .

Table 1. Comparison of mean (SD) values of the assayed biomarkers among the four studied groups

\begin{tabular}{|l|l|l|l|l|l|}
\hline Variables & Early RA & Late RA & OA & Control & p-value $^{\mathrm{a}}$ \\
\hline COMP, U/L & $18( \pm 10.6)$ & $19.3( \pm 9.6)$ & $10.9( \pm 4.5)$ & $4.2( \pm 3.8)$ & $<0.001$ \\
\hline ESR, mm/h & $23( \pm 2.8)$ & $24.9( \pm 2.2)$ & $13.6( \pm 5.2)$ & $12.8( \pm 2.3)$ & $<0.001$ \\
\hline RF, U/mL & $71( \pm 7.9)$ & $72( \pm 5.4)$ & $7.1( \pm 1.8)$ & $6.2( \pm 1.6)$ & $<0.001$ \\
\hline hs-CRP, mg/L & $1.8( \pm 0.2)$ & $2.2( \pm 0.3)$ & $0.92( \pm 0.43)$ & $0.4( \pm 0.3)$ & $<0.001$ \\
\hline anti-CCP, U/mL & $129( \pm 92)$ & $98( \pm 86)$ & $3.6( \pm 2.4)$ & $3( \pm 2.4)$ & $<0.001$ \\
\hline
\end{tabular}

Abbreviations: $\mathrm{RA}=$ rheumatoid arthritis; $\mathrm{OA}=$ osteoarthritis; $\mathrm{ESR}=$ erythrocyte sedimentation rate; Anti-CCP= anti-cyclic citrullinated peptide; $\mathrm{COMP}=$ Cartilage oligomeric matrix protein, ${ }^{\mathrm{a}}$ Analysis of variance (ANOVA)

Table 2. Correlation between the rheumatoid arthritis and osteoarthritis radiologic severity scores with the assayed biomarkers

\begin{tabular}{|l|l|l|l|l|l|l|}
\hline Severity scores & Correlation coefficient and significance & COMP & RF & ESR & hs-CRP & Anti-CCP \\
\hline \multirow{2}{*}{ OA severity score } & $\mathrm{R}$ & 0.621 & -0.061 & 0.417 & 0.042 & 0.042 \\
\cline { 2 - 7 } & $\mathrm{p}$-value & $<0.001$ & 0.774 & 0.038 & 0.484 & 0.883 \\
\hline \multirow{2}{*}{ Early RA SES score } & $\mathrm{R}$ & 0.753 & 0.585 & 0.330 & -0.086 & 0.775 \\
\cline { 2 - 7 } & $\mathrm{p}$-value & $<0.001$ & $<0.001$ & 0.021 & 0.557 & $<0.001$ \\
\hline \multirow{2}{*}{ Late RA SES score } & $\mathrm{R}$ & 0.677 & 0.672 & 0.295 & 0.331 & 0.794 \\
\cline { 2 - 7 } & $\mathrm{p}$-value & $<0.001$ & $<0.001$ & 0.036 & $<0.001$ & $<0.001$ \\
\hline
\end{tabular}

Abbreviation: $\mathrm{RA}=$ rheumatoid arthritis; $\mathrm{OA}=$ osteoarthritis; $\mathrm{ESR}=$ erythrocyte sedimentation rate; Anti-CCP $=$ anticyclic citrullinated peptide; $\mathrm{COMP}=$ Cartilage oligomeric matrix protein

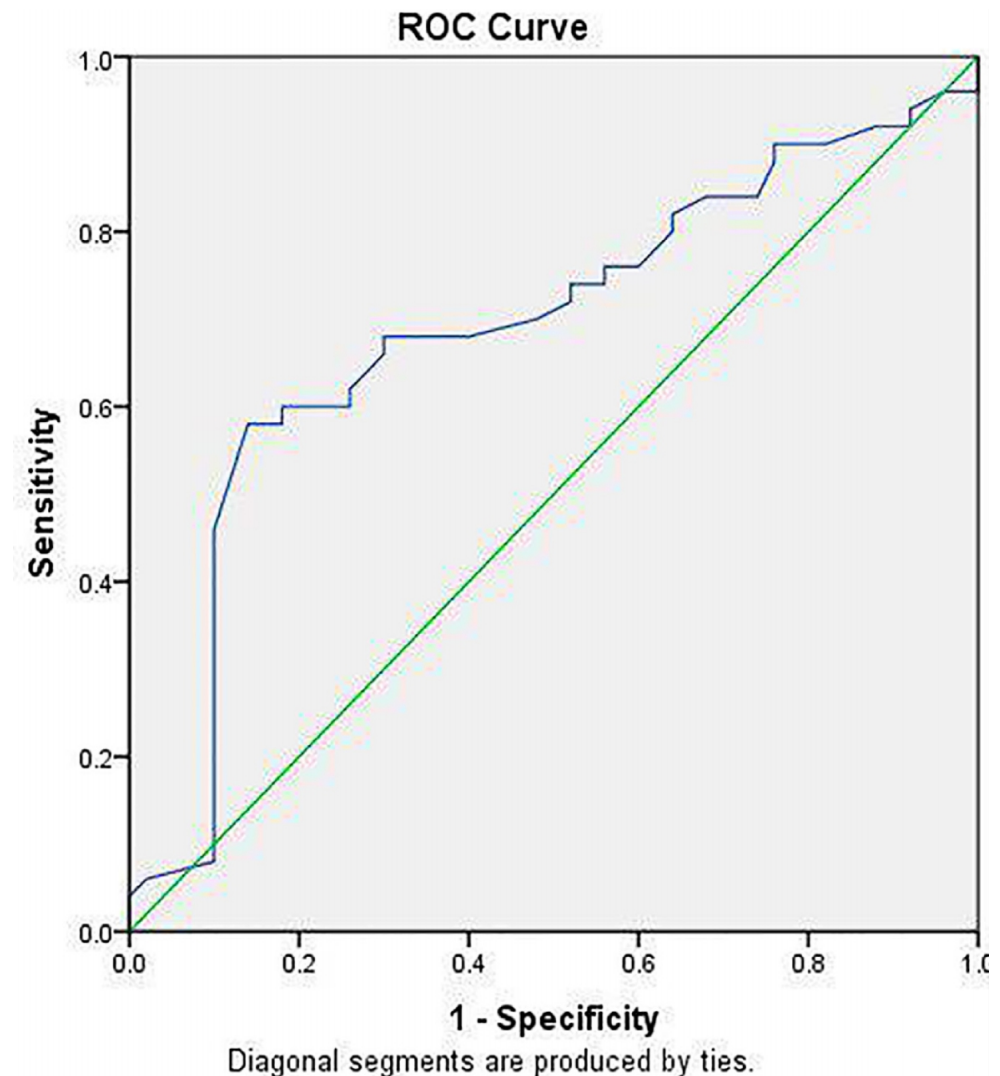

Figure 1. ROC analysis for serum cartilage oligomeric matrix protein (COMP) to for diagnosis of late rheumatoid arthritis (RA) with area under curve of $69 \%(\mathrm{p}=0.001)$ 
Table 3. Cut-off point and diagnostic accuracy of serum cartilage oligomeric matrix protein (COMP) in the diagnosis of late rheumatoid arthritis (RA)

\begin{tabular}{|l|l|l|l|l|l|}
\hline Optimal cut-off point (Youden index) & Sensitivity & Specificity & PPV & NPV & Positive LR \\
\hline 15.25 U/L & $68 \%$ & $72 \%$ & $70 \%$ & $69 \%$ & 2.42 \\
\hline
\end{tabular}

$\mathrm{PPV}=$ positive predictive value; $\mathrm{NPV}=$ negative predictive value; $\mathrm{LR}=$ likelihood ratio

\section{Discussion}

RA can be presented as a mild and non-destructive disease to a severe and rapidly destructive joint disease. Various new proposed biomarkers are used to choose the best treatment strategy and predict RA prognosis $(22,24,25)$. These biomarkers could be applied in clinical practice and research settings to manage therapeutic response and joint destruction and turnover progression. Based on the obtained results, serum COMP level was significantly higher among RA patients compared to OA and control subjects. In the subset of RA patients, COMP not only was higher in those with more advanced disease, but also had an acceptable sensitivity and specificity to diagnose RA patients with late-stage disease. Production of COMP is associated with duration of erosive joint damage in RA. Although there is evidence about the role of COMP in activating complement system which contributes to disease progression, the main impact of COMP in RA course is still unclear (10). COMP is released due to catabolic reaction and high turnover of cartilage matrix in RA (11). In later-stage RA, repair mechanisms cannot compensate joint destruction (26-29). (27) In agreement with our results, a recent study including RA and healthy controls, reported higher mean serum COMP level in RA group $(31.4 \mathrm{ng} / \mathrm{mL})$ in comparison to control group $(19.64 \mathrm{ng} / \mathrm{mL})$ (13). Here, we determined joint damage using validated radiographic scoring systems. However, in the mentioned study (13), knee cartilage thickness using ultrasound was used to assess joint damage which showed an inverse relationship with serum COMP level. A former study showed, comparable to our results, that serum COMP was higher in established RA $(23.9 \mathrm{micg} / \mathrm{mL})$ than in early-stage RA $15.1 \mathrm{micg} / \mathrm{mL})$. This study also evaluated synovial COMP level which showed similar results to serum COMP level (16). Our study revealed that there is a good positive correlation between this biomarker and joint destruction in late RA. In addition, serum COMP had an acceptable sensitivity and specificity at concentration of $15.2 \mathrm{U} / \mathrm{L}$ in diagnosing late-stage RA. Serum COMP is also helpful in diagnosis of early-stage RA. A previous study revealed that COMP had a specificity of $96 \%$ for diagnosing early RA defined as RA lasted less than 3 months when compared to healthy controls; however its sensitivity was only $44 \%$ (30). Considering this evidence, serum COMP appears a specific test for RA. However, our results suggest that serum COMP not only can be used for diagnosis of RA, but also, its higher concentration suggests more advanced joint cartilage damage. Therefore, in addition to some other clinical (such as Disease Activity Score-28) and radiologic scores that are currently used widely to monitor disease progression, serum COMP can also be measured to monitor patients. Measuring biological markers to determine cartilage formation and breakdown imbalance is an established practice in following patients to determine disease progression and therapeutic response, and even multi-biomarker disease activity (MBDA) has been proposed which was found to be concordant with MRI findings of joint damage (8). An Andersson et al. study revealed that a high level of COMP at diagnosis time is associated with cartilage and joint destruction over the next five years in RA patients (11). This emphasizes the prognostic value that COMP has in the course of RA progression. Here, as the study was of a crosssectional nature, we did not follow the patients to find out how serum COMP level can predict RA aggravation and its correlation with radiographic scoring worsening. Algergawy et al. defined COMP as prognostic and diagnostic marker in RA and showed that patients with established RA are more likely to have higher levels of COMP (27). On the other hand, anti-TNF and other biologic therapies (such as adalimumab and etanercept) could reduce COMP release from tissues and prevent further joint damage in RA patients $(31,32)$. In addition to radiographic scoring systems used extensively, DAS-28 is also a practical clinical tool to define RA severity. The significant correlation of serum COMP with DAS-28 has also been shown $(13,27)$. It has been studied and verified that as RA severity worsens (whether in early-stage (11) or late-stage RA), serum COMP level rises. The current results are compatible with this fact, as serum COMP level was much higher in later-stage RA compared to early-stage RA. However, we moved one step further to determine whether COMP can discriminate early-stage vs. late-stage RA. The ROC analyses showed that COMP, with good sensitivity and specificity, can be used for this purpose. This shows that COMP did not only reflect the cartilage involvement, but also it was associated with disease severity and joint cartilage damage. Using this biomarker in diagnosis, predicting joint cartilage damage and prognosis in RA patients can bring together a therapeutic guide to identify who might respond dramatically to a specific therapy and decrease drug related side effects and costs. 


\section{Study limitations}

We faced some limitations in this study. First, the nature of the study as a cross-sectional one did not allow us to follow the patients to observe the prognostic value of COMP. Also, we were not able to assay cytokines such as interleukins that may have association with both RA severity and COMP concentration.

\section{Conclusions}

The results of this study showed that serum COMP level has an acceptable sensitivity and specificity to diagnose RA patients with later and more advanced stage disease compared to patients with early-stage and less advanced RA. This biomarker can be used in clinical practice to determine joint damage severity in RA patients. We recommend further studies to use other imaging studies such as ultrasound to determine correlation between COMP and synovial thickness, and also to follow the patients over time to determine prognostic value of serum COMP level in RA patients.

\section{Acknowledgments:}

This article was extracted from the thesis of Dr. Mandana Khodashahi for degree of Subspecialty in Rheumatology, with registration number 511/1854 and research project code number 922799, supported by the Chancellor for Research of Mashhad University of Medical Science, Mashhad, Iran. We are grateful to all patients for their kind participation. Hereby we express our appreciation to the Vice Chancellor of Research, Mashhad University of Medical Sciences, for the financial and material support; and all those who helped us in this project. We are also grateful to all patients for their kind participation.

\section{Conflict of Interest:}

There is no conflict of interest to be declared.

\section{Authors' contributions:}

All authors contributed to this project and article equally. All authors read and approved the final manuscript.

\section{References:}

1) Rudan I, Sidhu S, Papana A, Meng SJ, Xin-Wei Y, Wang W, et al. Prevalence of rheumatoid arthritis in low- and middle-income countries: A systematic review and analysis. J Glob Health 2015;5 (1): 010409. PMid: 25969732, PMCid: PMC4416333

2) Pruijn GJ. Citrullination and carbamylation in the pathophysiology of rheumatoid arthritis. Front Immunol 2015; 6: 192. doi: 10.3389/fimmu.2015.00192, PMid: 25964785, PMCid: PMC4410602

3) Khanna R, Dlouhy BJ, Smith ZA, Lam SK, Koski TR, Dahdaleh NS. The impact of steroids, methotrexate, and biologics on clinical and radiographic outcomes in patients with rheumatoid arthritis undergoing fusions at the craniovertebral junction. J Craniovertebr Junction Spine 2015;6(2):60-4. doi: 10.4103/09748237.156044, PMid: 25972710, PMCid: PMC4426523

4) Van Vilsteren M, Boot CR, Knol DL, van Schaardenburg D, Voskuyl AE, Steenbeek R, et al. Productivity at work and quality of life in patients with rheumatoid arthritis. BMC Musculoskelet Disord 2015;16:107. doi: 10.1186/s12891-015-0562-x, PMid: 25940578, PMCid: PMC4425924

5) Gurol G, Ciftci IH, Harman H, Karakece E, Kamanli A, Tekeoglu I. Roles of claudin-5 and von Willebrand factor in patients with rheumatoid arthritis. Int J Clin Exp Pathol 2015;8(2):1979-84. PMid: 25973092, PMCid: PMC4396339

6) Mocelin V, Nisihara RM, Utiyama SR, Kotze LM, Ramos O, Jr., Messias-Reason I. Anti-CCP Antibodies and Rheumatological Findings in Brazilian Patients with Crohn's Disease. Digestion 2015;91(4):303 -6. doi: 10.1159/000369899, PMid: 25925094

7) Vignesh AP, Srinivasan R. Ocular manifestations of rheumatoid arthritis and their correlation with anticyclic citrullinated peptide antibodies. Clin Ophthalmol 2015;9:393-7. PMid: 25750517, PMCid: PMC4348132

8) Krabbe S, Bolce R, Brahe CH, Dohn UM, Ejbjerg BJ, Hetland ML, et al. Investigation of a multibiomarker disease activity score in rheumatoid arthritis by comparison with magnetic resonance imaging, computed tomography, ultrasonography, and radiography parameters of inflammation and damage. Scand J Rheumatol 2017;46(5):353-358. doi: 10.1080/03009742.2016.1211315, PMid: 27682742

9) Saxne T, Heinegard D. Cartilage oligomeric matrix protein: a novel marker of cartilage turnover detectable in synovial fluid and blood. Br J Rheumatol 1992;31(9):583-91. doi: 10.1093/rheumatology/31.9.583, PMid: 1381980 
10) Robinson WH, Lindstrom TM, Cheung RK, Sokolove J. Mechanistic biomarkers for clinical decision making in rheumatic diseases. Nat Rev Rheumatol 2013;9(5):267-76. doi: 10.1038/nrrheum.2013.14, PMid: 23419428, PMCid: PMC3673766

11) Andersson ML, Svensson B, Petersson IF, Hafstrom I, Albertsson K, Forslind K, et al. Early increase in serum-COMP is associated with joint damage progression over the first five years in patients with rheumatoid arthritis. BMC Musculoskelet Disord 2013;14:229. doi: 10.1186/1471-2474-14-229, PMid: 23915292, PMCid: PMC3750296

12) Wislowska M, Jablonska B. Serum cartilage oligomeric matrix protein (COMP) in rheumatoid arthritis and knee osteoarthritis. Clin Rheumatol 2005;24(3):278-84. doi: 10.1007/s10067-004-1000-x, PMid: 15940561

13) Sakthiswary R, Rajalingam S, Hussein H, Sridharan R, Asrul AW. Cartilage oligomeric matrix protein (COMP) in rheumatoid arthritis and its correlation with sonographic knee cartilage thickness and disease activity. Clin Rheumatol 2017. doi: 10.1007/s10067-017-3817-0, PMid: 28889184

14) Skoumal M, Kolarz G, Klingler A. Serum levels of cartilage oligomeric matrix protein. A predicting factor and a valuable parameter for disease management in rheumatoid arthritis. Scand $\mathrm{J}$ Rheumatol 2003;32(3):156-61. doi: 10.1080/03009740310002498, PMid: 12892252

15) Syversen SW, Goll GL, van der Heijde D, Landewe R, Gaarder PI, Odegard S, et al. Cartilage and bone biomarkers in rheumatoid arthritis: prediction of 10-year radiographic progression. J Rheumatol 2009;36(2):266-72. doi: 10.3899/jrheum.080180, PMid: 19132792

16) El Defrawy AO, Gheita TA, Raslan HM, El Ansary MM, El Awar AH. Serum and synovial cartilage oligomeric matrix protein levels in early and established rheumatoid arthritis. $Z$ Rheumatol 2016;75(9):917-923. doi: 10.1007/s00393-015-1647-5, PMid: 26683321

17) Aletaha D, Neogi T, Silman AJ, Funovits J, Felson DT, Bingham CO, 3rd, et al. 2010 Rheumatoid arthritis classification criteria: an American College of Rheumatology/European League Against Rheumatism collaborative initiative. Arthritis Rheum 2010;62(9):2569-81. doi: 10.1002/art.27584, PMid: 20872595

18) Altman R, Asch E, Bloch D, Bole G, Borenstein D, Brandt K, et al. Development of criteria for the classification and reporting of osteoarthritis. Classification of osteoarthritis of the knee. Diagnostic and Therapeutic Criteria Committee of the American Rheumatism Association. Arthritis Rheum 1986;29(8):1039-49. doi: 10.1002/art.1780290816, PMid: 3741515

19) Young-Min S, Cawston T, Marshall N, Coady D, Christgau S, Saxne T, et al. Biomarkers predict radiographic progression in early rheumatoid arthritis and perform well compared with traditional markers. Arthritis Rheum 2007;56(10):3236-47. doi: 10.1002/art.22923, PMid: 17907159

20) Harrison M. Erythrocyte sedimentation rate and C-reactive protein. Aust Prescr 2015;38(3):93-4. doi: 10.18773/austprescr.2015.034, PMid: 26648629, PMCid: PMC4653962

21) Braschi E, Shojania K, Allan GM. Anti-CCP: a truly helpful rheumatoid arthritis test? Can Fam Physician 2016;62(3):234. PMid: 26975916, PMCid: PMC4984588

22) Wolfe F, van der Heijde DM, Larsen A. Assessing radiographic status of rheumatoid arthritis: introduction of a short erosion scale. J Rheumatol 2000;27(9):2090-9. PMid: 10990218

23) Schiphof D, Boers M, Bierma-Zeinstra SM. Differences in descriptions of Kellgren and Lawrence grades of knee osteoarthritis. Ann Rheum Dis 2008;67(7):1034-6. doi: 10.1136/ard.2007.079020, PMid: 18198197

24) Christensen AF, Lindegaard H, Horslev-Petersen K, Hetland ML, Ejbjerg B, Stengaard-Pedersen K, et al. Cartilage oligomeric matrix protein associates differentially with erosions and synovitis and has a different temporal course in cyclic citrullinated peptide antibody (anti-CCP)-positive versus anti-CCP-negative early rheumatoid arthritis. J Rheumatol 2011;38(8):1563-8. doi: 10.3899/jrheum.101241, PMid: 21572145

25) Krabben A, Huizinga TW, Mil AH. Biomarkers for radiographic progression in rheumatoid arthritis. Curr Pharm Des 2015;21(2):147-69. doi: 10.2174/1381612820666140825122525, PMid: 25163742

26) Papamichael K, Tsirogianni A, Papasteriades C, Mantzaris GJ. Low prevalence of antibodies to cyclic citrullinated peptide in patients with inflammatory bowel disease regardless of the presence of arthritis. Eur J Gastroenterol Hepatol 2010;22(6):705-9. PMid: 19525851

27) Algergawy SA, Abd El-Sabour M, Osman AS, Emam SM, Elham N. Early diagnostic and prognostic values of anti-cyclic citrullinated peptide antibody and cartilage oligomeric matrix protein in rheumatoid arthritis. Egypt J Immunol 2013;20(2):11-20. PMid: 24617043

28) Denarie D, Constant E, Thomas T, Marotte H. Could biomarkers of bone, cartilage or synovium turnover be used for relapse prediction in rheumatoid arthritis patients? 2014;2014:537324.

29) Vilim V, Vytasek R, Olejarova M, Machacek S, Gatterova J, Prochazka B, et al. Serum cartilage oligomeric matrix protein reflects the presence of clinically diagnosed synovitis in patients with knee osteoarthritis. Osteoarthritis Cartilage 2001;9(7):612-8. doi: 10.1053/joca.2001.0434, PMid: 11597173 
30) Soderlin MK, Kastbom A, Kautiainen H, Leirisalo-Repo M, Strandberg G, Skogh T. Antibodies against cyclic citrullinated peptide (CCP) and levels of cartilage oligomeric matrix protein (COMP) in very early arthritis: relation to diagnosis and disease activity. Scand J Rheumatol 2004;33(3):185-8. doi: 10.1080/03009740310004856, PMid: 15228190

31) Jilani AA, Mackworth-Young CG. The role of citrullinated protein antibodies in predicting erosive disease in rheumatoid arthritis: a systematic literature review and meta-analysis. Int $\mathrm{J}$ Rheumatol 2015;2015:728610. doi: 10.1155/2015/728610, PMid: 25821469, PMCid: PMC4364370

32) Acharya C, Yik JH, Kishore A, Van Dinh V, Di Cesare PE, Haudenschild DR. Cartilage oligomeric matrix protein and its binding partners in the cartilage extracellular matrix: interaction, regulation and role in chondrogenesis. Matrix Biol 2014;37:102-11. doi: 10.1016/j.matbio.2014.06.001, PMid: 24997222 